\title{
Pengaruh Faktor Kualitas Jasa Perguruan Tinggi Jarak Jauh (PTJ) terhadap Kepuasan Mahasiswa dan Niat Menyelesaikan Kuliah (Studi Kasus Mahasiswa Fakultas Ekonomi Universitas Terbuka)
}

\author{
Maya Maria \\ Fakultas Ekonomi, Universitas Terbuka \\ Jalan Cabe Raya, Tangerang Selatan \\ e-mail: maya.maria.ut2014@gmail.com \\ Rini Dwiyani Hadiwidjaja \\ Fakultas Ekonomi, Universitas Terbuka \\ Jalan Cabe Raya, Tangerang Selatan \\ Andy Mulyana \\ Fakultas Ekonomi, Universitas Terbuka \\ Jalan Cabe Raya, Tangerang Selatan
}

\begin{abstract}
This study aims to determine the effects of open distance learning service quality dimensions consisting of the way of learning, tutoring and teaching, modules, student services, programs of study, tuition and fees, physical facilities to student satisfaction and the behavioral intentions of completing the study at Universitas Terbuka (UT). This research analysis units were the students of the Faculty of Economic, Universitas Terbuka (FEKON-UT) who registered in 2012 with a population of 2085 people. The method of sample selection was convenience sampling method to the college students who have taken at least one semester. The data were analyzed from 161 respondents spread in 7 UPBJJ-UT throughout Indonesia with a certain proportion. To obtain the data, this study used survey methods of primary data and secondary data. Analysis tool to test the hypothesis is a structural equation modelling (SEM) with Partial Least Square (PLS). The finding of this studywere the significance effects on : 1) the quality of services to satisfaction of students; 2) the quality of services to the intention of completing studying at UT; and 3) student satisfaction to the intention of completing college at UT.

Keywords: service quality, student satisfaction, open distance learning, intention to finish college
\end{abstract}

\section{ABSTRAK}

Penelitian ini bertujuan untuk mengetahui pengaruh faktor-faktor kualitas jasa yang terdiri dari cara belajar, tutor dan pengajaran, modul, layanan mahasiswa, program studi, biaya, dan fasilitas fisik terhadap kepuasan mahasiswa dan niat menyelesaikan kuliah di Universitas Terbuka (UT). Unit analisis penelitian adalah mahasiswa Fakultas Ekonomi Universitas Terbuka (FEKON-UT) masa registrasi 2012, dengan populasi sejumlah 2085 orang. Metode pemilihan sampel adalah metode convenience sampling yang merupakan metode pengambilan sampel yang didasarkan pada kriteria tertentu, yaitu mahasiswa yang telah menempuh kuliah minimal 1 (satu) semester. Jumlah sampel penelitian ini sebanyak 161 mahasiswa yang tersebar pada 7 (tujuh) Unit Program Belajar Jarak Jauh (UPBJJ-UT) di seluruh Indonesia dengan proporsi tertentu. Untuk mendapatkan data, penelitian ini menggunakan metode survei data primer dan data sekunder. Alat analisis untuk menguji hipotesis adalah model persamaan struktural (SEM) dengan Partial Least Square (PLS). Temuan dari penelitian ini adalah terdapat pengaruh yang signifikan antara : 1) kualitas jasa terhadap kepuasan mahasiswa; 2) kualitas jasa terhadap niat menyelesaikan kuliah di UT; dan 3) kepuasan terhadap niat menyelesaikan kuliah di UT.

Kata kunci:k ualitas jasa, kepuasan mahasiswa, pendidikan terbuka jarak jauh, niat menyelesaikan kuliah 


\section{Pendahuluan}

Perguruan tinggi merupakan institusi pendidikan yang bergerak di sektor jasa. Seiring kecenderungan di sektor jasa, perhatian terhadap kualitas jasa institusi pendidikan tinggi juga semakin meningkat (O'Neill dan Palmer 2004). Salah satu ukuran kinerja terpenting pada institusi pendidikan tinggi adalah kepuasan mahasiswa terkait dengan program dan layanan yang diberikan (Seeman dan O'Hara 2006). Hill (1995) dalam Brochado (2009) menyatakan mahasiswa adalah pelanggan utama dari sebuah universitas. Mahasiswa merupakan penerima langsung dari jasa yang disediakan. Oleh karena itu, persepsi kualitas jasa mahasiswa menjadi isu sangat penting bagi universitas dan pengelolanya. Institusi pendidikan tinggi sebagai industri jasa harus memiliki fiturfitur klasik jasa dengan pengukuran kualitas jasa yang kompleks.

Menurut Oliver (1997), kepuasan adalah penilaian bahwa fitur produk atau jasa, atau produk atau jasa itu sendiri, memberikan tingkat pemenuhan berkaitan dengan konsumsi yang menyenangkan termasuk tingkat under-fulfillment dan over-fulfillment. Selanjutnya, Halstead et al. (1994) menyatakan kepuasan adalah respons afektif yang sifatnya transaction-specific dan dihasilkan dari pembandingan yang dilakukan konsumen antara kinerja produk dengan beberapa standar pembelian. Sedangkan Fornell (1992) menyatakan kepuasan pelanggan adalah evaluasi purnabeli keseluruhan. Terakhir, Parasuraman et al. (1988) mendefinisikan kepuasan pelanggan sebagai pembanding antara layanan yang diharapkan (expectation) dan kinerja (perceived performance). Dalam konteks jasa, kualitas didefinisikan sebagai perbandingan antara jasa yang diberikan dengan ekspekstasi pelanggan (Lewis dan Booms 1983 dalam Berry et al. 1983). Pengukuran kualitas jasa institusi Open Distance Learning (ODL) telah dilakukan Bahroom et al. (2009) di Open University Malaysia (OUM). Hasil pentingnya adalah institusi ODL memenuhi ekspektasi siswa berkaitan dengan kualifikasi akademik yang mana faktor empati menunjukkan item yang berhubungan dengan masalah pendekatan, kurangnya kontak, ketersediaan, perhatian dan kenyamanan.

Universitas Terbuka (UT) menyadari kualitas jasa yang diberikan secara konsisten akan mengarah kepada sikap positif, baik penerima maupun pemberi jasa. Bahroom et al. (2009) menyatakan kualitas jasa sangat penting bagi institusi pendidikan tinggi, dan lebih penting bagi pendidikan tinggi jarak jauh (PTJJ). Hal ini disebabkan karena tingkat putus kuliah PTJJ lebih tinggi dibandingkan dengan perguruan tinggi konvensional. Komitmen UT terhadap kualitas jasa terlihat dari akreditasi dan sertifikasi kualitas, baik dalam maupun luar negeri. Badan Akreditasi Nasional Perguruan Tinggi (BAN-PT) telah memberikan akreditasi terhadap seluruh program studi UT. Selain itu, UT berhasil mempertahankan sertifikasi kualitas manajemen ISO 9001:2000/2008 dan sertifikasi The International Council for Open and Distance Education (ICDE) hingga saat ini. Walaupun telah berupaya keras meningkatkan dan mempertahankan kualitas jasa pendidikan yang diberikan, disisi lain keluhan mahasiswa sebagai pelanggan masih kerap ditemui. Berdasarkan data forum komunitas Fakultas Ekonomi UT (FEKON-UT) 2009-2011, mayoritas keluhan mahasiswa terkait dengan layanan bantuan belajar yang terdiri dari tutorial tatap muka (TTM), tutorial online (Tuton), dan tugas akhir program (TAP). Keluhan layanan Tuton menjadi sorotan, karena banyak mahasiswa mengeluhkan kesulitan akses internet, proses aktivasi, keterlambatan inisiasi, dan kesulitan unggah tugas. 


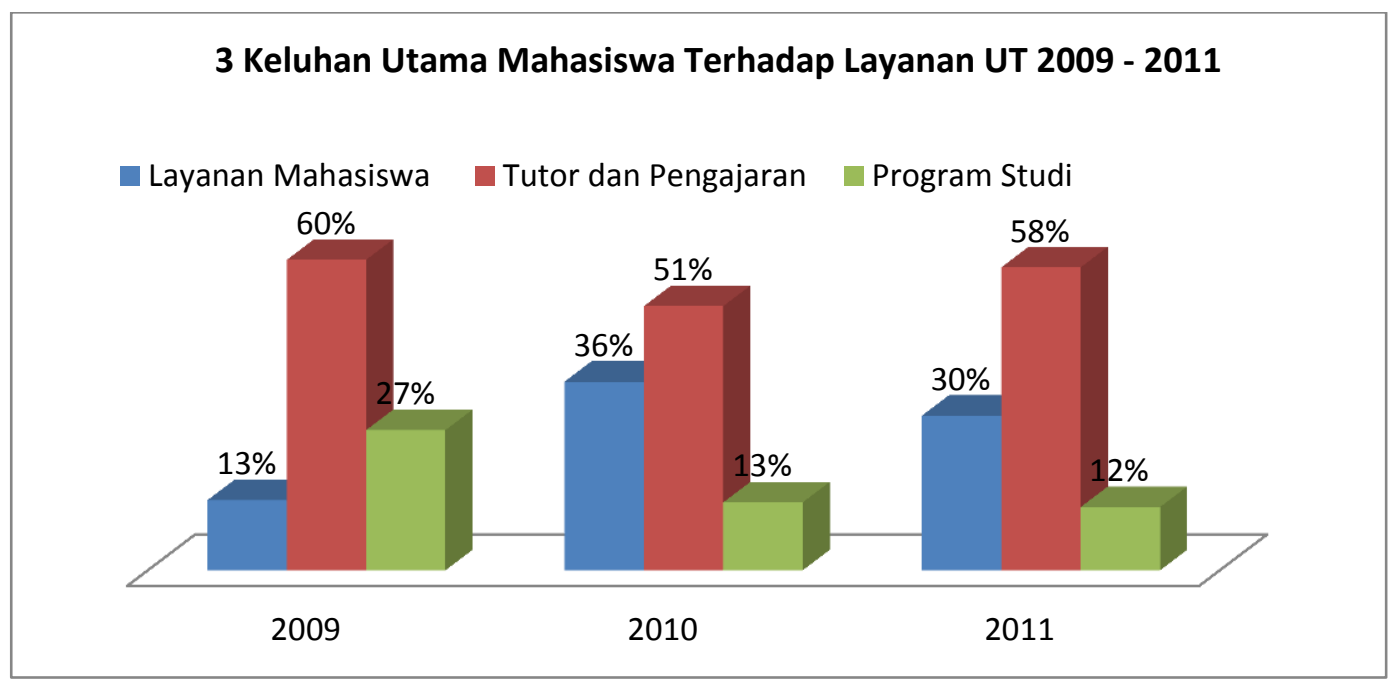

Gambar 1. Keluhan mahasiswa terhadap layanan UT 2009 - 2011

Tampak pada Gambar 1, keluhan mahasiswa terhadap layanan bantuan belajar relatif stabil dari tahun ke tahun. Walaupun begitu, keluhan-keluhan mahasiswa tersebut perlu dikelola dengan baik. Berikut ini kutipan testimonial beberapa mahasiswa dalam forum komunitas, menyatakan tidak nyaman dan kurang memberikan pelayanan yang optimal dalam proses pembayaran uang kuliah melalui salah satu Bank BUMN yang bekerjasama dengan UT. Ketidakpuasan juga diungkapkan oleh mahasiswa terkait dengan fasilitas fisik, di antaranya penggunaan gedung-gedung sekolah yang kurang layak untuk proses belajar mengajar.

Berdasarkan permasalahan tersebut, penelitian ini bertujuan untuk menganalisis pengaruh kualitas jasa pendidikan terhadap kepuasan mahasiswa dan niat menyelesaikan kuliah. Variabel kualitas jasa yang digunakan dalam penelitian mendasarkan instrumen pengukuran kualitas jasa pendidikan tinggi jarak jauh (PTJJ) yang telah dikembangkan oleh Latif (2004) dan Bahroom et al. (2009) dengan studi pada Open University Malaysia (OUM). Hal ini dikarenakan karakteristik kualitas jasa PTJJ berbeda dengan perguruan tinggi konvensional. Kualitas jasa PTJJ terdiri dari 7 (tujuh) dimensi dibandingkan 5 (lima) dimensi pada perguruan tinggi konvensional. Ke-tujuh dimensi tersebut adalah cara belajar, tutor dan pengajaran, modul, layanan mahasiswa, program studi, biaya, dan fasilitas fisik. Untuk itu penelitian ini menggunakan 7 (tujuh) dimensi tersebut sebagai faktor-faktor kualitas jasa PTJJ yang dianalisis pengaruhnya terhadap kepuasan mahasiswa dan niat menyelesaikan kuliah di UT.

Niat menyelesaikan kuliah di UT ini menjadi variabel yang penting diteliti berdasarkan model Zeithaml et al. (1996) yang mana niat perilaku dapat diidentifikasi sebagai niat pembelian kembali, informasi dari mulut ke mulut, loyalitas, perilaku keluhan, dan sensitivitas harga. Kualitas pelayanan tinggi (seperti yang dilihat oleh pelanggan) sering menyebabkan niat perilaku menguntungkan, sementara kualitas layanan yang rendah cenderung mengarah ke niat perilaku yang tidak menguntungkan. Zeithaml et al. (1996) lebih menekankan bahwa niat perilaku dapat dilihat ketika pelanggan memutuskan untuk tetap dengan atau beralih produk. Burton et al. (2003) menyimpulkan bahwa pengalaman pelanggan terkait dengan niat perilaku. Pengalaman pelanggan yang lebih positif, semakin besar kemungkinan dia bersedia untuk 
menggunakan kembali layanan. Pernyataan seperti "Menggunakan jasa pendidikan UT di masa mendatang"; "Merekomendasikan UT kepada orang lain"; dan "Apabila memungkinkan untuk memilih kembali, saya akan tetap memilih UT sebagai tempat menuntut ilmu saat ini", digunakan untuk mengukur niat perilaku responden dalam penelitian ini. Inti dalam penelitian ini, niat berperilaku lebih dikaitkan dengan niat responden untuk tetap menyelesaikan kuliah di UT setelah mengetahui kepuasan responden terhadap kualitas layanan UT.

Interelasi atau hubungan timbal balik antara kualitas jasa, kepuasan mahasiswa, dan niat menyelesaikan kuliah mendasarkan pada hasil kajian dari Cronin dan Taylor (1992), Cronin et al. (2000), Bolton and Drew (1991), Dabholkar et al. (2000), Olorunniwo et al. (2006) yang menjelaskan bahwa kualitas jasa dan kepuasan memiliki kaitan langsung ke niat berperilaku (SQ dan SAT $\rightarrow$ BI). Di samping itu, Cronin et al. (2000), Brady and Robertson (2001), dan Olorunniwo et al. (2006) menunjukkan bahwa kepuasan merupakan variabel perantara antara kualitas jasa dan niat berperilaku (SQ $\rightarrow$ SAT $\rightarrow$ BI). Berdasar studi literatur beragam penelitian tersebut, maka model konseptual dari penelitian ini tampak pada Gambar 2.

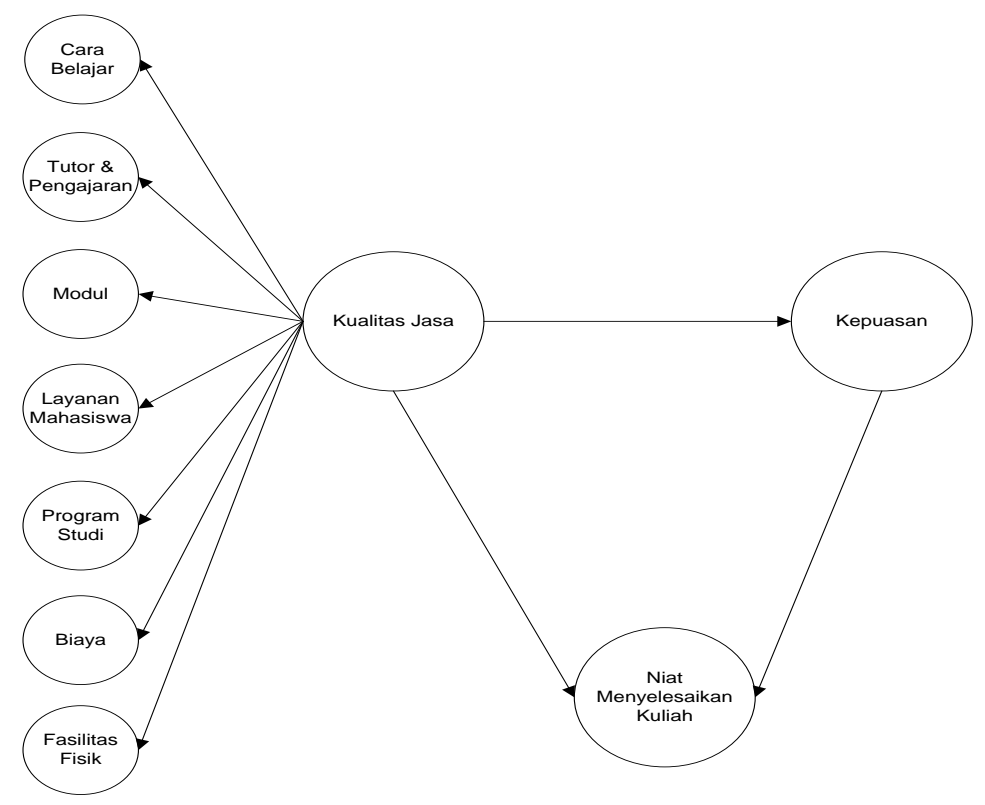

Gambar 2. Model konseptual

Hubungan antar variabel yang diuji dalam penelitian ini dijelaskan melalui hipotesis berdasarkan model konseptual tersebut yaitu sebagai berikut :

$\mathrm{H} 1$ : Diduga kualitas jasa berpengaruh terhadap kepuasan mahasiswa.

$\mathrm{H} 2$ : Diduga kualitas jasa berpengaruh terhadap niat menyelesaikan kuliah

H3 : Diduga kepuasan mahasiswa berpengaruh terhadap niat menyelesaikan kuliah

\section{Metode Penelitian}

Penelitian ini mengenai kualitas jasa, kepuasan dan niat menyelesaikan kuliah di UT sebagai perguruan tinggi jarak jauh. Pengujian interrelasi ketiga konstruk dilakukan 
dengan menggunakan analisis Structural Equation Modelling (SEM). Penelitian dilakukan di 7 (tujuh) Unit Program Belajar Jarak Jauh (UPBJJ-UT) di seluruh Indonesia. Ketujuh UPBJJ terpilih merupakan representasi kategori UPBJJ besar, sedang, dan kecil. Sampel diharapkan dapat mewakili populasi. Ketujuh UPBJJ yang dimaksud adalah UPBJJ-UT Jakarta, Bandung, Bali, Serang, Batam, Ambon dan Jayapura. Penelitian berlangsung selama 3 (tiga) bulan di masa registrasi 2012 yaitu bulan April-Juni 2012.

Data yang dikumpulkan pada penelitian ini adalah data primer dan data sekunder yang bersifat kualitatif dan kuantitatif. Data primer diperoleh langsung peneliti dari pembagian kuesioner di lapangan. Sedangkan data sekunder diperoleh dari literaturliteratur, buku-buku, artikel-artikel dan bahan pustaka lainnya.

Penelitian ini menggunakan metode survei, dengan menggunakan kuesioner sebagai instrumen penelitian. Penggunaan metode ini dilakukan dengan membagikan kuesioner pada mahasiswa peserta tutorial tatap muka (TTM). Populasi penelitian adalah mahasiswa FEKON-UT masa registrasi 2012. Data yang diperoleh dari Biro Administrasi dan Akademik Perencanaan dan Monitoring UT (BAAPM-UT). Jumlah mahasiswa FEKONUT masa registrasi 2012 adalah 2085 orang sehingga jumlah responden yang diambil minimum sebanyak 100 responden. Metode pemilihan sampel yang digunakan adalah metode non probability sampling dengan menggunakan purposive sampling. Jumlah sampel yang diambil dihitung menggunakan rumus Slovin dengan tingkat signifikansi kesalahan $10 \%$.

Sebelum kuesioner digunakan, terlebih dulu dilakukan pengujian kuesioner dengan uji validitas dan reliabilitas. Kedua uji tersebut melibatkan 30 responden berasal dari UPBJJ-UT Jakarta. Pengujian validitas dan reliabilitas menunjukkan seluruh item pertanyaan valid dan reliabel karena memiliki nilai corrected item total correlation lebih besar dari 0.361 dan nilai alpha cronbach lebih dari 0.70 .

Pada penelitian ini terdapat 3 (tiga) konstruk, yaitu konstruk kualitas jasa, kepuasan mahasiswa dan niat menyelesaikan kuliah. Seluruh konstruk diukur dengan first order yang bersifat reflektif. Konstruk kualitas jasa diukur menggunakan model pengukuran second order. Kualitas jasa diukur oleh 7 (tujuh) dimensi, yaitu cara belajar, tutor dan pengajaran, modul, layanan mahasiswa, program studi, biaya, dan fasilitas fisik. Penjabaran lengkap indikator per konstruk dapat dilihat pada Tabel 1.

Konstruk second order kualitas jasa diukur terdiri dari 7 (tujuh) dimensi memiliki 50 indikator yang dikembangkan oleh Latif (2004) serta Bahroom et al. (2009). Sedangkan 7 (tujuh) indikator konstruk kepuasan mengadaptasi penelitian Athiyaman (1997) dan Bettencourt (1997). Terakhir, kontruk niat menyelesaikan kuliah didasari oleh 3 (tiga) indikator yang dikembangkan Olorunniwo et al. (2006), sehingga secara total terdapat 60 indikator untuk mengukur ketiga konsruk yang ada. Seluruh indikator disusun dalam 1 (satu) set kuesioner. Jawaban dari responden bersifat kualitatif kemudian dikuantitatifkan dengan memberikan skor pada masing-masing jawaban. Skor jawaban menggunakan 5 poin skala Likert (Sekaran dan Bougie 2006). 
Tabel 1. Penjabaran atribut

\begin{tabular}{|c|c|c|}
\hline Konstruk & Dimensi/Indikator & Kode \\
\hline \multirow[t]{9}{*}{ Kualitas jasa } & 1. Cara belajar & $\mathrm{CB} 1, \mathrm{CB} 2, \mathrm{CB} 3, \mathrm{CB} 4, \mathrm{CB} 5$ \\
\hline & 2. Tutor dan pengajaran & $\begin{array}{l}\text { TP6, TP7, TP8, TP9, TP10, } \\
\text { TP11, TP12 }\end{array}$ \\
\hline & 3. Modul & $\begin{array}{l}\text { MDL15, MDL16, MDL17, } \\
\text { MDL18 }\end{array}$ \\
\hline & 4. Layanan mahasiswa & $\begin{array}{l}\text { LM20, LM21, LM22, LN23, } \\
\text { LM24, LM25, LM26, LM27, } \\
\text { LM28, LM29, LM30 }\end{array}$ \\
\hline & 5. Program studi & PS31, PS32, PS33, PS34, \\
\hline & & PS35, PS36, PS37, PS38, \\
\hline & & PS39, PS40 \\
\hline & 6. Biaya & $\begin{array}{l}\text { BYA41, BYA42, BYA43, } \\
\text { BYA44, BYA45 }\end{array}$ \\
\hline & 7. Fasilitas fisik & FS46, FS47, FS48, FS49, FS50 \\
\hline \multirow[t]{7}{*}{ Kepuasan mahasiswa } & $\begin{array}{l}\text { 1. Saya merasa puas atas keputusan saya } \\
\text { kuliah di Universitas Terbuka saat ini }\end{array}$ & KEP51 \\
\hline & $\begin{array}{l}\text { 2. Apabila mungkin, saya akan tetap mendaftar } \\
\text { di Universitas Terbuka saat ini }\end{array}$ & KEP52 \\
\hline & $\begin{array}{l}\text { 3. Saya merasa pilihan saya mendaftar di } \\
\text { Universitas Terbuka saat ini adalah tepat }\end{array}$ & KEP53 \\
\hline & $\begin{array}{l}\text { 4. Saya tidak menyesal telah mendaftar di } \\
\text { Universitas Terbuka saat ini }\end{array}$ & KEP54 \\
\hline & $\begin{array}{l}\text { 5. Saya merasa keputusan mendaftar di } \\
\text { Universitas Terbuka saat ini adalah tepat }\end{array}$ & KEP55 \\
\hline & $\begin{array}{l}\text { 6. Anda tidak bahagia mendaftar di Universitas } \\
\text { Terbuka saat ini }\end{array}$ & KEP56 \\
\hline & $\begin{array}{l}\text { 7. Dibandingkan dengan perguruan tinggi lain, } \\
\text { saya sangat puas kuliah di Universitas } \\
\text { Terbuka }\end{array}$ & KEP57 \\
\hline \multirow[t]{3}{*}{$\begin{array}{l}\text { Niat Menyelesaikan } \\
\text { Kuliah }\end{array}$} & $\begin{array}{l}\text { 1. Menggunakan jasa pendidikan UT di masa } \\
\text { mendatang }\end{array}$ & NB1 \\
\hline & 2. Merekomendasikan UT kepada orang lain & NB2 \\
\hline & $\begin{array}{l}\text { 3. Apabila memungkinkan untuk memilih } \\
\text { kembali, saya akan tetap memilih UT sebagai } \\
\text { tempat menuntut ilmu saat ini }\end{array}$ & NB3 \\
\hline
\end{tabular}

Pada penelitian ini SmartPLS digunakan untuk menganalisis hipotesis dengan model SEM. Secara umum ada 2 (dua) evaluasi model yang dilakukan yaitu outer model (model pengukuran) dan inner model (model struktural). Outer model dilakukan dengan menganalisis convergent validity, discriminant validity, dan composite reliability. Selanjutnya, inner model menganalisis beberapa kriteria yaitu nilai signifikansi masingmasing indikator, nilai signifikansi hubungan antar variabel laten dan R-square (Ghozali 2008). 


\section{Hasil dan Pembahasan}

III.1. Karakteristik Responden

Penelitian ini menggunakan data primer yang diperoleh melalui kuesioner. Dari 198 kuesioner yang kembali, hanya 161 yang memenuhi syarat untuk diolah. Profil responden secara lengkap dapat dilihat pada Tabel 2.

Tabel 2 menunjukkan jumlah responden pria sebanyak 83 responden (52\%) dan wanita 78 responden (48\%). Tingkat umur mahasiswa FEKON-UT sebagai responden beragam dari usia dibawah 20 tahun sampai dengan di atas 30 tahun. Rata-rata status pernikahan mahasiswa FEKON-UT cenderung lebih banyak belum nikah (54\%) daripada sudah nikah (46\%). Sedangkan dari jenis pekerjaan mahasiswa FEKON-UT sebagian besar adalah pegawai swasta (45\%) dan PNS (20\%). Tingkat pendidikan terakhir paling banyak dari SMA dan sederajat (75\%) dan mahasiswa FEKON-UT yang sering melakukan kunjungan ke kantor UPBJJ-UT merupakan salah satu sikap recreationist yaitu melakukan kunjungan berulang. Selain mengetahui niat berperilaku mahasiswa, kunjungan mahasiswa ini dapat juga dijadikan alat ukur fasilitas fisik yang dimiliki oleh kantor UPBJJUT. Berdasarkan Tabel 2 dapat ditunjukkan bahwa frekuensi kunjungan ke pusat layanan UT lebih dari 4 (empat) kali menduduki urutan terbesar (31\%) atau 50 responden.

Tabel 2. Profil responden

\begin{tabular}{|c|c|c|c|}
\hline No & Keterangan & Jumlah Responden & $\%$ \\
\hline \multirow[t]{3}{*}{1} & Jenis Kelamin & & \\
\hline & Pria & 83 & 52 \\
\hline & Wanita & 78 & 48 \\
\hline \multirow[t]{5}{*}{2} & Tingkat Umur & & \\
\hline & $<21$ tahun & 39 & 24 \\
\hline & $21-25$ tahun & 42 & 26 \\
\hline & 26 - 30 tahun & 37 & 23 \\
\hline & $>30$ tahun & 43 & 27 \\
\hline \multirow[t]{3}{*}{3} & Status Penikahan & & \\
\hline & Belum Nikah & 87 & 54 \\
\hline & Nikah & 74 & 46 \\
\hline \multirow[t]{8}{*}{4} & Jenis Pekerjaan & & \\
\hline & Belum Bekerja & 25 & 16 \\
\hline & BUMN & 2 & 1 \\
\hline & Guru & 1 & 1 \\
\hline & PNS & 33 & 20 \\
\hline & Pegawai Swasta & 72 & 45 \\
\hline & Wiraswasta & 10 & 6 \\
\hline & Lain-Lain & 18 & 11 \\
\hline \multirow[t]{4}{*}{5} & Pendidikan Terakhir & & \\
\hline & SMA dan Sederajat & 120 & 75 \\
\hline & Diploma & 38 & 24 \\
\hline & Sarjana & 3 & 2 \\
\hline \multirow[t]{5}{*}{6} & IPK & & \\
\hline & $<2.00$ & 26 & 16 \\
\hline & $2.00-2.49$ & 71 & 44 \\
\hline & $2.50-2.90$ & 47 & 29 \\
\hline & $>2.99$ & 17 & 11 \\
\hline
\end{tabular}


Lanjutan Tabel 2

\begin{tabular}{clcc}
\hline No & \multicolumn{1}{c}{ Keterangan } & Jumlah Responden & $\%$ \\
\hline 7 & Frekuensi Berkunjung Ke Pusat Layanan UT & & \\
& $>4$ kali & 50 & 31 \\
& 4 kali & 13 & 8 \\
& 3 kali & 36 & 22 \\
& 2 kali & 42 & 26 \\
& kali & 20 & 12 \\
\hline
\end{tabular}

Sumber : Hasil diolah (2012)

\section{III.2. Analisis Partial Least Square (PLS)}

Analisis PLS digunakan untuk menguji interrelasi antar variabel laten dengan variabel laten serta variabel laten dengan indikator-indikatornya. Model PLS penelitian ini dibuat berdasarkan data mahasiswa peserta TTM sebanyak 161 responden.

1. Analisis Model Pengukuran (Outer Model)

Pemeriksaan terhadap model pengukuran adalah melihat convergent validity, discriminant validity dan composite reliability.

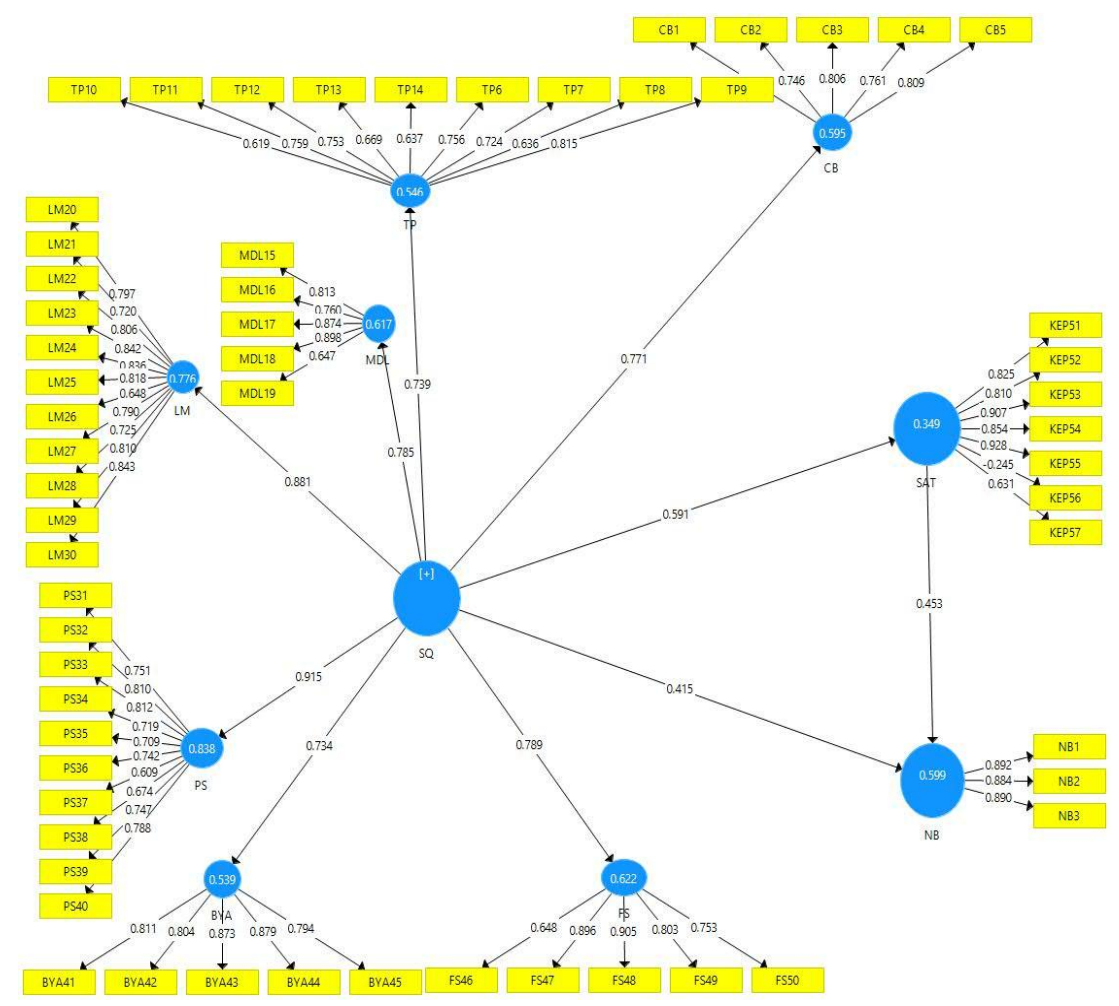

Gambar 3. Model awal untuk penghitungan algoritma PLS

a. Convergent Validity

Convergent validity dari model pengukuran refleksif indikator dinilai berdasarkan korelasi item score/component score yang diestimasi dengan software SmartPLS 3.0. Dalam penelitian ini digunakan batas loading factor sebesar 0.70 (Ghozali 2011). Dari hasil analisis dengan calculate PLS Algorithm diperoleh hasil seperti Gambar 4. 
Kemudian dilakukan eksekusi berulang sehingga diperoleh nilai akhir loading $\geq 0.7$ untuk masing-masing indikator dan diperoleh hasil akhir sebagai berikut.

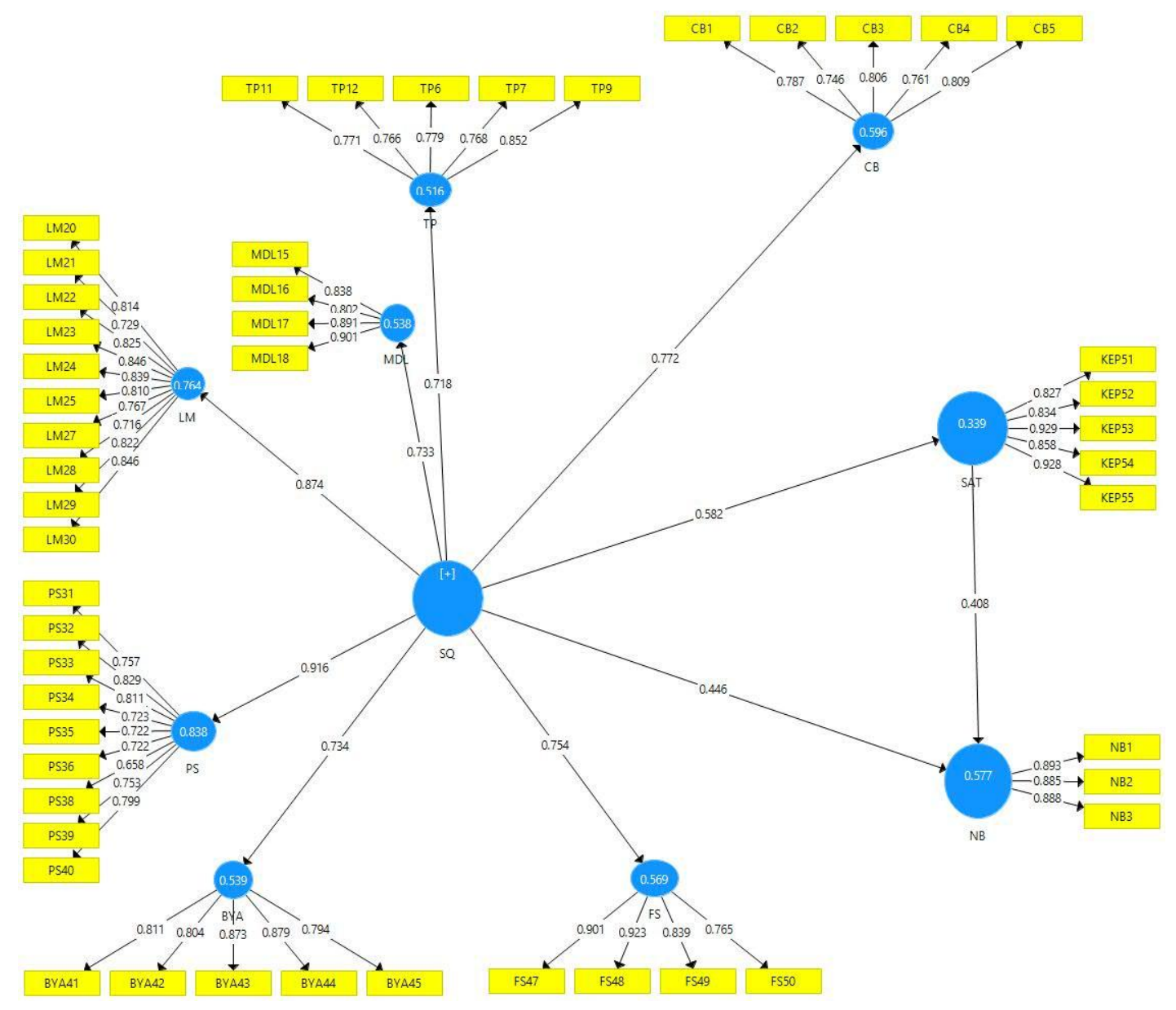

Gambar 4. Hasil penghitungan akhir algoritma PLS

Terlihat pada Gambar 4, terdapat 11 indikator atau variabel dengan loading factor bernilai kurang 0.7 yang dibuang yaitu TP8, TP10, TP13, TP14, MDL19, LM26, PS37, PS38, FS46, KEP56, KEP57 dan model sudah dapat dikatakan stabil. Hasil penelitian berdasarkan Gambar 4 di atas, yaitu di antara pengaruh langsung antara variabel kualitas jasa dan kepuasan mahasiswa terhadap niat menyelesaikan kuliah, maka variabel kualitas jasa (0.446) lebih dominan mempengaruhi dibanding variabel kepuasan (0.446). Namun demikian, pengaruh langsung kualitas jasa terhadap kepuasan menunjukkan angka yang lebih tinggi (0.582). Adapun pengaruh tidak langsung antara kualitas jasa terhadap niat dengan melalui kepuasan yaitu sebesar 0.237 (lebih kecil pengaruhnya dibanding pengaruh langsung).

Faktor-faktor yang dianggap mahasiswa paling berpengaruh terhadap kualitas jasa UT berdasar nilai loading factor yaitu dengan urutan sebagai berikut : tawaran produk program studi (0.916), layanan mahasiswa (0.874), cara belajar (0.772), fasilitas fisik (0.754), biaya (0.734), modul (0.733), dan yang terakhir tutor dan pengajaran (0.718). Menurut mahasiswa, tiga indikator yang paling berpengaruh terhadap kualitas dimensi tawaran program studi, secara berturut-turut adalah 
kemenarikan matakuliah (0.829), tawaran program studi yang beragam, spesifik dan berkualitas (0.811), dan kemudahan mendapat informasi mengenai program studi (0.799). Adapun indikator-indikator yang paling berpengaruh terhadapkualitas dimensi layanan mahasiswa, secara berurutan adalah keefektifan dan kemudahan akses berkomunikasi dengan UT (0.846), keefektifan dan efisiensi pelayananan registrasi (0.846), kecepatan respon/penanganan terhadap pertanyaan/pengaduan dan penyelesaian masalah mahasiswa dengan baik (0.839), kesopanan, itikad membantu, keefektifan komunikasi dari petugas/staf UT yang baik (0.825), kemudahan akses dan efisiensi teknologi UT (internet, SLI UT, e-mail, dan lain-lain) untuk diperolehnya informasi terakhir UT secara online (0.822), dan efisiensi pelayanan mahasiswa (Pelma) (0.814). Pada dimesi cara belajar, tiga indikator yang dianggap paling berpengaruh terhadap kualitas cara belajar mahasiswa adalah kombinasi cara belajar efektif (0.809), kenyamanan pilihan cara belajar (0.806), kenyamanan pribadi belajar mandiri (0.787).

Tiga indikator fasilitas fisik yang paling dominan mempengaruhi kualitas fasilitas fisik yang dirasakan adalah kenyamanan meja penerima layanan mahasiswa (0.923), kenyamanan tata letak ruang pelayanan mahasiswa (0.901), kemudahan untuk menjangkau kantor UPBJJ-UT (0.839). Pada dimensi biaya, indikator yang paling dominan mempengaruhi kualitas jasa dalam hal biaya pendidikan di UT menurut mahasiswa secara berurutuan adalah fleksibilitas waktu dan cara pembayaran biaya kuliah (0.879), kenyamanan sarana dan cara pembayaran biaya kuliah nyaman (0.873), beban biaya pendidikan per sks yang wajar (0.811), efisiensi pelayanan pembayaran biaya pendidikan melalui billing system (0.794). Pada dimensi modul, indikator-indikator yang paling dominan mempengaruhi kualitas modul/bahan ajar cetak UT adalah gaya kualitas penulisan modul yang baik $(0.838)$, dan materi modul jelas dan menarik (0.891). Sementara itu, pada dimensi tutor dan pengajaran, indikator-indikator yang dianggap paling berpengaruh terhadap nilai kualitas tutor dan pengajaran oleh mahasiswa secara berurutan adalah Tutor Tutorial Tatap Muka (TTM) atau Tutorial Online (Tuton) berkompeten dan berpengetahuan luas sehingga dapat berkomunikasi baik (0.852), metode pengajaran tutor TTM dan Tuton yang efektif dan inovatif (0.779), mahasiswa dan tutor berhubungan dengan baik (0.771), Tutor TTM atau Tuton membantu dan mendorong mahasiswa untuk belajar (0.768), Tutor memberikan umpan balik yang efektif terhadap proses belajar mahasiswa dalam forum diskusi online dan tugas (0.766).

b. Discriminant validity

Discriminant validity digunakan untuk memastikan bahwa setiap konsep dari variabel laten/konstruk berbeda dengan variabel laten lainnya. Model mempunyai discriminant validity yang baik jika setiap nilai loading dari setiap indikator dari sebuah variabel laten memiliki nilai loading yang paling besar dengan nilai loading lain terhadap variabel latennya.

Pada Tabel 3 dapat dilihat berdasarkan hasil output SmartPLS, semua konstruk nilai akarAverage Variance Extracted (AVE) lebih besar dari nilai korelasi maksimum konstruk, sehingga dapat dikatakan bahwa kesepuluh konstruk (kualitas jasa, kepuasan, niat menyelesaikan kuliah, cara belajar, tutorial dan pengajaran, modul, 
layanan mahasiswa, program studi, biaya dan fasilitas fisik) memiliki tingkat discriminant validity yang tinggi.

Tabel 3. Average Variance Extracted

\begin{tabular}{lcc}
\hline Variabel Laten & AVE & Akar AVE \\
\hline BYA & 0.694 & 0.833 \\
CB & 0.612 & 0.782 \\
FS & 0.738 & 0.859 \\
LM & 0.644 & 0.803 \\
MDL & 0.738 & 0.859 \\
NB & 0.790 & 0.889 \\
PS & 0.569 & 0.754 \\
SAT & 0.768 & 0.877 \\
SQ & 0.399 & 0.632 \\
TP & 0.621 & 0.788 \\
\hline
\end{tabular}

c. Composite Reliability

Kriteria validitas dan reliabilitas dapat juga dilihat dari nilai reliabilitas suatu indikator dari masing-masing variabel laten. Indikator dari variabel laten dikatakan memiliki reliabilitas tinggi jika nilainya 0.70 .

Tabel 4. Composite reliability

\begin{tabular}{lc}
\hline Variabel Laten & Composite Reliability \\
\hline BYA & 0.919 \\
CB & 0.887 \\
FS & 0.918 \\
LM & 0.948 \\
MDL & 0.918 \\
NB & 0.918 \\
PS & 0.922 \\
SAT & 0.943 \\
SQ & 0.970 \\
TP & 0.891 \\
\hline
\end{tabular}

Berdasarkan Tabel 4 di atas, bahwa semua variabel adalah reliabel karena nilai composite reliability di atas 0.70 sebagaimana direkomendasi-kan. Dengan demikian, semua konstruk telah memenuhi convergent validity dan discriminant validity yang tinggi sehingga dapat dilanjutkan untuk analisis inner model.

2. Analisis Model Struktural (Inner Model)

Pengujian inner model dilakukan untuk melihat nilai signifikansi masing-masing indikator dengan uji $t$, signifikansi hubungan antara variabel laten dengan uji t sesuai parameter jalur strukturalnya dan nilai $R$-square dari model penelitian. Pengujian tersebut dilakukan menggunakan SmartPLS 3.0 dengan melakukan langkah calculate bootstrapping dan diperoleh hasil sebagai berikut. 


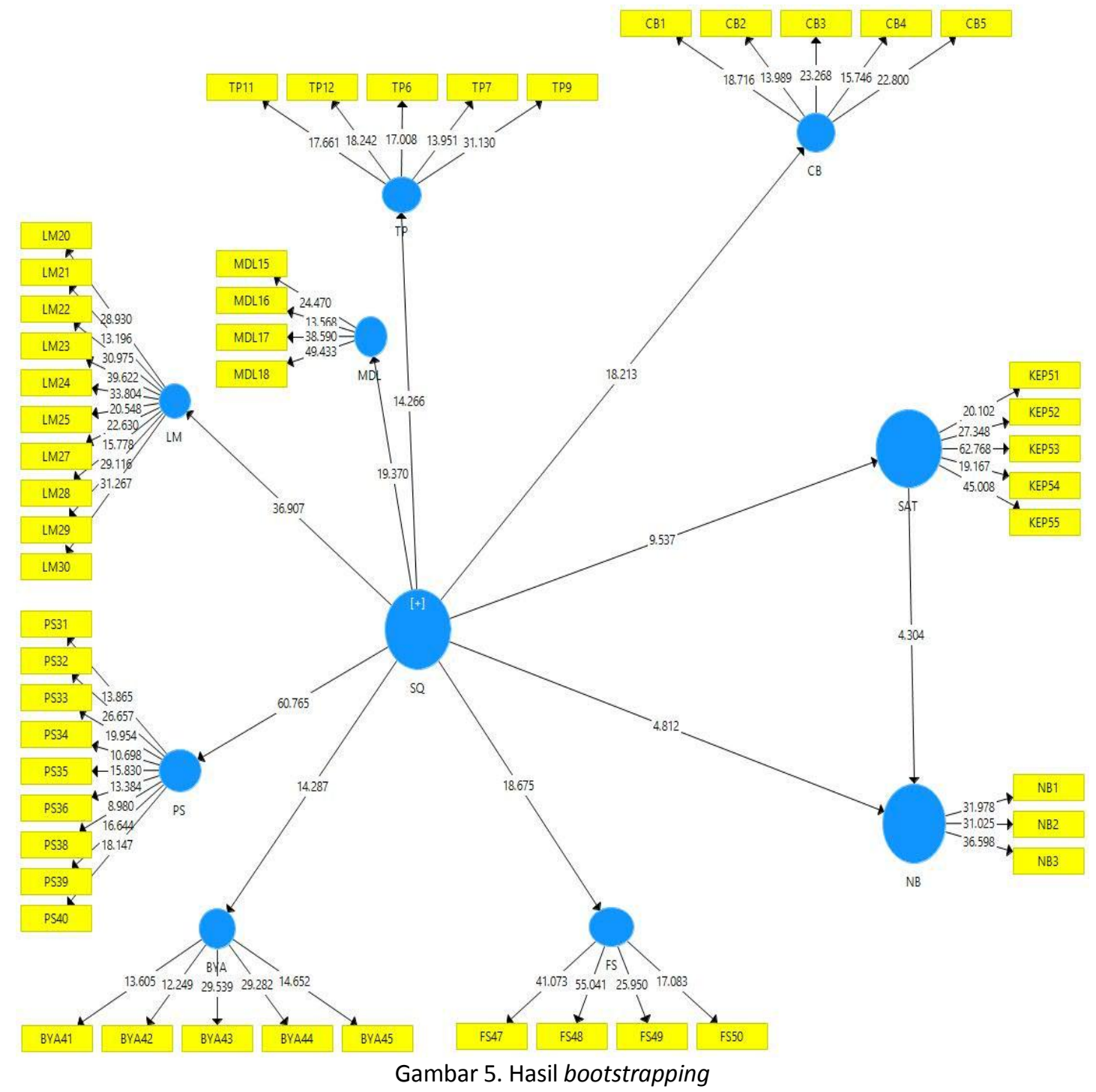

Penilaian dan pengujian hasil dari perhitungan bootstrapping pada SmartPLS 3.0 adalah sebagai berikut :

a. Nilai signifikansi masing-masing indikator

Diperoleh dari hasil perhitungan t-statistik pada masing-masing indikator pada kelompok masing-masing variabel latennya dengan ketentuan dianggap indikator tersebut signifikan jika nilai t-statistik $>1.96$ (pada alpha 5\%).

Berdasarkan hasil olahan data, menunjukkan semua indikator-indikator memiliki nilai t-statistik > 1.96, yang berarti bahwa semua indikator tersebut mempunyai nilai yang signifikan.

b. Nilai signifikansi hubungan antar variabel laten.

Berdasarkan Gambar 5 di atas, 3 (tiga) parameter jalur hubungan yang menjadi hipotesis pada penelitian ini bernilai statistik $>1.96$ yang menunjukkan signifikansi hubungan antar variabel. 
Tabel 5. Path coefficient

\begin{tabular}{lcl}
\multicolumn{1}{c}{ Jalur } & t-value & \multicolumn{1}{c}{ Kesimpulan } \\
\hline Kualitas jasa $\rightarrow$ kepuasan & 9.537 & Signifikan, Hipotesis 1 diterima \\
Kualitas jasa $\rightarrow$ niat & 4.812 & Signifikan, Hipotesis 2 diterima \\
Kepuasan $\rightarrow$ niat & 4.304 & Signifikan, Hipotesis 3 diterima \\
\hline
\end{tabular}

1) Pengaruh Kualitas Jasa terhadap Kepuasan Mahasiswa

Berdasarkan Tabel 5, diketahui bahwa kualitas jasa terbukti secara signifikan mempunyai pengaruh terhadap kepuasan mahasiswa. Hasil ini sesuai dengan prediksi bahwa kualitas jasa berpengaruh terhadap kepuasan mahasiswa. Tujuh indikator kualitas jasa (cara belajar, tutor dan pengajaran, modul, layanan mahasiswa, program studi, biaya, dan fasilitas fisik) di UT didesain agar mahasiswa mendapatkan kualitas pendidikan yang memadai melalui metode pembelajaran jarak jauh dan mempermudah bagi mahasiswa UT yang sebagian besar telah bekerja. Hasil penelitian ini mendukung temuan Latif (2004). Temuan penelitian ini juga mendukung hasil riset Abdullah (2006) yang memperkenalkan alternatif pengukuran kualitas jasa pendidikan yang disebut Higher Education Performance (HedPERF) di mana tidak hanya mempertimbangkan komponen akademik, tetapi juga aspek lingkungan jasa total seperti yang dialami siswa sebagai aspek non akademik, selain akademik, reputasi, akses, dan isu-isu program.

2) Kualitas Jasa terhadap Niat Menyelesaikan Kuliah

Tabel 5 menunjukkan bahwa $\mathrm{H} 2$ terbukti signifikan, hal ini memberikan bukti bahwa tujuh indikator kualias jasa berpengaruh terhadap niat mahasiswa menyelesaikan kuliah. Dengan demikian tujuh dimensi kualitas jasa (cara belajar, tutor dan pengajaran, modul, layanan mahasiswa, program studi, biaya, dan fasilitas fisik) di UT dirasakan mahasiswa dapat membuat mereka mempunyai keyakinan untuk terus menyelesaikan studi dan merekomendasikan UT kepada orang lain. Hasil ini konsisten dengan penelitian sebelumnya yang dilakukan Olorunniwo et al. (2006) yang menemukan bahwa kualitas jasa signifikan mempengaruhi niat berperilaku pada layanan jasa masal.

3) Pengaruh Kepuasan Mahasiswa terhadap Niat Menyelesaikan Kuliah

Tabel 5 menunjukkan H3 terbukti signifikan. Penelitian ini membuktikan bahwa kepuasan mahasiswa berpengaruh pada niat menyelesaikan kuliah. Dengan demikian niat menyelesaikan kuliah di UT merupakan imbas setelah mahasiswa puas terhadap kualitas layanan UT. Hasil ini sejalan dengan temuan Burton et al. (2003) menyimpulkan bahwa pengalaman pelanggan terkait dengan niat berperilaku. Pengalaman pelanggan yang lebih positif yang membuat merasa puas, semakin membuat pelanggan bersedia untuk menggunakan kembali layanan jasa yang bersangkutan. Mahasiswa UT yang merasa puas diindikasikan mempunyai niat berperilaku untuk terus menggunakan jasa pendidikan UT di masa mendatang, merekomendasikan UT kepada orang lain, dan tetap memilih UT sebagai tempat menuntut ilmu.

c. R-square

Pengujian terhadap inner model dilakukan dengan melihat $R$-square yang merupakan uji goodness fit model. 
Tabel 6. R-Square

\begin{tabular}{lc}
\hline Variabel Laten & R-Square \\
\hline NB & 0.577 \\
SAT & 0.339 \\
\hline
\end{tabular}

Tabel 6 di atas menunjukkan $R$-square variabel laten niat menyelesaikan kuliah (NB) sebesar 0.577. Hal ini menunjukkan bahwa variabel laten kualitas jasa dan kepuasan berhubungan sebesar $\mathbf{5 7 . 7 \%}$ terhadap niat menyelesaikan kuliah. Sedangkan sisanya dijelaskan oleh variabel lain yang tidak termasuk dalam penelitian ini. Sementara nilai $R$-square untuk variabel laten kepuasan didapatkan nilai 0.339. Hal ini berarti bahwa variabel laten kualitas jasa berhubungan sebesar 33.9\% terhadap kepuasan. Sedangkan sisanya dijelaskan oleh variabel lain yang tidak termasuk dalam penelitian.

\section{III.3. Implikasi Manajerial}

Salah satu ukuran kinerja terpenting pada institusi pendidikan tinggi adalah kepuasan mahasiswa terkait dengan program dan layanan yang diberikan (Seeman dan O'Hara 2006). Untuk meningkatkan kepuasan mahasiswa, kualitas jasa yang ditawarkan UT perlu diperhatikan dengan baik. Bahroom et al. (2009) menyatakan kualitas jasa sangat penting bagi institusi pendidikan tinggi, dan lebih penting bagi pendidikan tinggi jarak jauh (PTJJ). Hasil penelitian menunjukkan, UT perlu terus meningkatkan kualitas jasa karena berpengaruh secara signifikan terhadap kepuasan mahasiswa dan juga terhadap niat menyelesaikan kuliah. Tujuh dimensi kualitas jasa (cara belajar, tutor dan pengajaran, modul, layanan mahasiswa, program studi, biaya, dan fasilitas fisik) perlu diperhatikan oleh UT agar mahasiswa puas dan akhirnya tetap melanjutkan kuliah di UT, juga merekomendasikan UT ke orang lain. Apalagi temuan penelitian menunjukkan pengaruh langsung variabel kualitas jasa lebih dominan mempengaruhi terhadap niat menyelesaikan kuliah dibanding variabel kepuasan.

Berdasarkan hasil penelitian ini, maka UT perlu memperhatikan urutan dimensi kualitas jasa yang mempengaruhi kepuasan mahasiswa dan niat melanjutkan kuliah, yaitu berturut-turut dimulai dari dimensi tawaran produk program studi, layanan mahasiswa, cara belajar, fasilitas fisik, biaya pendidikan, modul, dan yang terakhir tutor dan pengajaran. Hal ini menunjukkan tawaran program studi antara lain kemenarikan mata kuliah, ragam dan kualitas program studi, dan kemudahan mendapat informasi mengenai program studi menjadi faktor-faktor yang perlu dipertahankan kualitasnya agar mahasiswa merasa puas dan tetap berkeinginan melanjutkan studi. Dalam hal ini, UT dapat melakukan studi analisis kebutuhan pasar dan pendapat pakar untuk menawarkan paket kurikulum yang menarik.

UT juga harus terus meningkatkan kualitas layanan mahasiswa seperti keefektifan dalam berkomunikasi, pelayananan registrasi, kecepatan respon/penanganan terhadap pertanyaan/pengaduan dan penyelesaian masalah mahasiswa dengan baik, kepedulian petugas/staf UT, akses terhadap teknologi informasi UT, dan efisiensi pelayanan mahasiswa. Berkenaan dengan metode pembelajaran jarak jauh UT, maka faktor-faktor berikut perlu terus ditingkatkan kualitasnya karena dianggap paling berpengaruh terhadap kualitas cara belajar mahasiswa seperti kombinasi cara belajar tutorial online 
dan tatap muka, kenyamanan pilihan cara belajar, dan kenyaman dalam belajar mandiri. UT sebaiknya meningkatkan sosialisasi pilihan cara pembelajaran yang ditetapkan oleh pengelola perguruan tinggi, baik melalui tutorial tatap muka maupun tutorial online.

Sedangkan yang berkaitan atribut fisik, UT sebaiknya terus meningkatkan kualitas fasilitas fisik kepada mahasiswanya, antara lain dengan tetap memperhatikan front desk layanan mahasiswa, pengaturan tata letak ruang pelayanan yang nyaman, dan keterjangkauan jarak tempuh kantor UPBJJ-UT. Adapun dari aspek biaya pendidikan, maka UT diharapkan terus memperhatikan beragam faktor seperti fleksibilitas waktu dan cara pembayaran biaya kuliah, kenyamanan sarana dan cara pembayaran biaya kuliah, dan kewajaran beban biaya pendidikan per sks, serta efisiensi pelayanan pembayaran biaya pendidikan melalui billing system. Dengan demikian salah satu karakteristik UT yaitu biaya pendidikan yang terjangkau, tetap perlu dipertahankan.

Sebagai institusi pendidikan jarak jauh yang menekankan kualitas bahan ajar mandiri, maka UT perlu terus mempertahankan kualitas modulnya yang dianggap mahasiswa sudah bagus, terutama dalam hal gaya penulisan dan uraian materi modul yang jelas dan menarik. Modul UT memang menjadi hal penting dalam pembelajaran jarak jauh dikarenakan modul UT didesain sebagai self-instructioned (seluruh materi secara instruksional dapat dipelajari sendiri) dan self contained (seluruh substansi mahasiswa tersedia di modul). Sementara itu, dari aspek proses belajar mengajar, UT harus tetap meningkatkan nilai kualitas tutor dan pengajaran oleh mahasiswa terutama dalam hal kompetensi Tutor Tutorial Tatap Muka (TTM) atau Tutorial Online (Tuton), efektifitas dan inovasi metode pengajaran tutor TTM dan Tuton, komunikasi yang baik antara mahasiswa dan tutor, peran serta Tutor TTM atau Tuton dalam membantu dan mendorong mahasiswa untuk belajar, dan kemauan tutor untuk memberikan umpan balik yang efektif terhadap proses belajar mahasiswa dalam forum diskusi online dan tugas. Mahasiswa menganggap tutor kurang efektif memberikan umpan balik terhadap proses belajar mahasiswa (forum diskusi online dan tugas), maka hal ini menjadi masukan bagi UT ke depannya.

\section{Kesimpulan}

Berdasarkan hasil penelitian, kualias jasa berpengaruh secara signifikan terhadap kepuasan mahasiswa. Demikian juga kualitas jasa juga berpengaruh signifikan terhadap niat menyelesaikan kuliah, dan kepuasan mahasiswa pada akhirnya berpengaruh signifikan terhadap niat menyelesaikan kuliah di UT. Kualitas jasa UT sebagai penyelenggara pendidikan terbuka dan jarak jauh, mendapat perhatian mahasiswa paling besar dari aspek layanan program studi dan selanjutnya berturut-turut pada aspek layanan mahasiswa, cara belajar, fasilitas fisik, biaya pendidikan, modul, dan yang terakhir tutor dan pengajaran.

Saran yang dapat dilakukan UT ke depan berdasarkan temuan penelitian ini antara lain ketepatan waktu pengumuman hasil UAS dan penilaian yang valid, dimana hal ini terkait dengan efektifitas dan efisiensi pelayanan pusat pengujian. Selain itu dalam hal layanan mahasiswa, ke depannya UT perlu lebih meningkatkan akses kemudahan mahasiswa mendapatkan informasi secara online cara melalui efektifitas dan efisiensi teknologi UT (internet, SLI UT, e-mail, dan lain-lain). Langkah perbaikan untuk 
peningkatan kepuasan mahasiswa juga dapat dilakukan dengan cara tutor aktif memberikan umpan balik yang efektif terhadap proses belajar mahasiswa. Dari metode pembelajaran, hal-hal yang perlu diperbaiki adalah mendorong dan memotivasi mahasiswa dalam belajar mandiri dengan kombinasi cara belajar yang efektif baik melalui Tuton atau TTM.

\section{Daftar Pustaka}

Abdullah F. 2006. The development of HEdPERF: a new measuring instrument of service quality for the higher education sector. International Journal of Consumer Studies, 30: 569-581.

Athiyaman A. 1997. Linking student satisfaction and service quality perceptions: the case of university education. European Journal of Marketing, 31(7): 528-540.

Bahroom R, Latif LA, San Ng M. 2009. ODLPERF: An instrument for measuring service quality in an Open and Distance Learning (ODL) institution. $23^{\text {rd }}$ AAOU Annual Conference, Teheran, 3-5 November 2009.

Berry LT, Shostak GL, Upah GD. 1983. Emerging perspectives on services marketing, Chicago (US): IL, American Marketing Association.

Bettencourt LA. 1997. Customer voluntary performance: Customer as partners in service delivery. Journal of Retailing, 73 (3): 383-406.

Bolton RN, Drew JH. 1991. A multistage model of customer's assessments of service quality and value. Journal of Consumer Research, 17(4): 875-884.

Brady MK, Robertson CJ. 2001. Searching for a consensus on the antecedent role of service quality and satisfaction: an exploratory cross national study. Journal of Business Research, 51(1): 53-60.

Brochado A. 2009. Comparing alternative instruments to measure service quality in higher education. Quality Assurance in Education, 17(2): 174-190.DOI: 10. 1108/09684880910951381.

Burton S, Sheather S, Roberts J. 2003. Reality or Perception? The effect of actual and perceived performance on satisfaction and behavioral intentions. Journal of Service Research, 5(4): 292-302. DOI: 10.1177/1094670503005004002.

Cronin JJ Jr, Brady MK, Hult TM. 2000. Assessing the effects of quality, value, customer satisfaction on consumer behavioral intentions in service environment. Journal of Retailing, 76(2): 193-216.

Cronin JJ, Taylor SA. 1992. Measuring service quality: re-examination and extension. Journal of Marketing, 56(3): 56-68.DOI: 10.2307/1252296.

Dabholkar PA, Shepherd CD, Thorpe DI. 2000. A comprehensive framework for service quality: an investigation of critical conceptual and measurement issues through a longitudinal study. Journal of Retailing, 76(2): 139-173.doi:10. 1016/S00224359(00)00029-4.

Fornell C. 1992. A national satisfaction barometer: the Swedish experience. J. Mark., 56(1): 6-21.DOI: 10.2307/1252129.

Ghozali I. 2011. Aplikasi Analisis Multivariate Dengan Program IBM SPSS 19. Edisi kelima. Semarang (ID): BP Universitas Diponegoro. 
Ghozali I. 2008. Model Persamaan: Konsep dan Aplikasi dengan Program AMOS 16. Semarang (ID): Badan Penerbit UNDIP

Halstead D, Hartman D, Schmidt SL. 1994. Multisource Effects on the Satisfaction Formation Process. Journal of the Academy of Marketing Science, 22(2): 114-129.

Latif LA. 2004. Perceived Service Quality and Satisfaction in Distance Education - in $9^{\text {th }}$ International Research Symposium On Service Quality (QUIS9).

O’Neill M, Palmer A. 2004. Importance-performance analysis: a useful tool for directing continuous quality improvement in higher education. Quality Assurance in Education, 12(1): 39-52.

Oliver RL. 1997. Satisfaction: A Behavioral Perspective on the Consumer. New York (US): McGraw-Hill.

Olorunniwo F, Hsu MK, Udo GJ. 2006. Service quality, customer satisfaction, and behavioral intentions in the service factory. Journal of Services Marketing, 20(1): 59-72.

Parasuraman A, Zeithaml VA, Berry LL. 1988. SERVQUAL: A multiple-item scale for measuring consumer perceptions of services quality. Journal of Retailing, 64(1): 12-40.

Rashid MdZA, Harun H. 2004. Service quality in the Open and Distance Learning - The perspective of learners in Malaysia, Open University Malaysia Research Report, 129.

Seeman ED, O'Hara M. 2006. Customer relationship management in higher education. Campus-Wide Information Systems, 23(1): 24-34. http://dx.doi.org/10.1108/ 10650740610639714.

Sekaran U, Bougie R. 2006. Research Methods for Business: A Skill Building Approach. West Sussex (UK): JohnWiley \& Sons.

Zeithaml VA, Berry LL, Parasuraman A. 1996. The behavioral consequences of service quality. Journal of Marketing. 60(2): 31-46. 